\title{
Why do we observe significant differences between measured and 'back-calculated' properties of natural fibres?
}

\author{
Darshil U. Shah $\mathbb{D} \cdot$ Ranajit K. Nag • \\ Mike J. Clifford
}

Received: 29 December 2015/ Accepted: 24 March 2016/Published online: 30 March 2016

(C) The Author(s) 2016. This article is published with open access at Springerlink.com

\begin{abstract}
The drive towards sustainability, even in materials technologies, has fuelled an increasing interest in bio-based composites. Cellulosic fibres, such as flax and jute, are being considered as alternatives to technical synthetic fibres, such as glass, as reinforcements in fibre reinforced polymer composites for a wide range of applications. A critical bottleneck in the advancement of plant fibre composites (PFRPs) is our current inability to predict PFRP properties from data on fibre properties. This is highly desirable in the cost- and time-effective development and design of optimised PFRP materials with reliable behaviour. This study, alongside limited other studies in literature, have found that the experimentally determined (through single fibre tests) fibre properties are significantly different from the predicted ('backcalculated' using the popular rule-of-mixtures) fibre properties for plant fibres. In this note, we explore potential sources of the observed discrepancy and
\end{abstract}

\section{U. Shah $(\bowtie)$}

Centre for Natural Material Innovation, Department of Architecture, University of Cambridge,

Cambridge CB2 1PX, UK

e-mail: darshil.shah@hotmail.co.uk;

dus20@cam.ac.uk

\section{R. K. Nag · M. J. Clifford}

Polymer Composites Group, Division of Materials, Mechanics and Structures, Faculty of Engineering, The University of Nottingham, Nottingham NG7 2RD, UK identify the more likely origins relating to both measurement and errors in predictions based on the rule-of-mixtures. The explored content in this discussion facilitates the design of a future investigation to (1) identify the sensitivity of the discrepancy between measured and predicted fibre properties to the various potential origins, (2) form a unified hypothesis on the observed phenomenon, and (3) determine whether the rule-of-mixtures model (in specific cases) can be improved and may be able to predict properties precisely.

Keywords Plant fibre $\cdot$ Natural fibre composites · Biocomposites $\cdot$ Rule-of-mixtures model

\section{Introduction}

An abundant number of plant fibres are available on Earth from more than 1000 species of plants. While not all these plant fibres are useable, their most widespread is for textiles, pulp and paper products, insulation and animal husbandry (Lewin 2007). Owing to the impressive techno-ecological profile of cellulosic plant fibres (Fig. 1), in some cases making them competitive to even glass fibres, in recent years there has been a revival in interest in the development of plant fibre reinforced polymer composites (PFRPs) for a variety of applications (Faruk et al. 2012; Shah 2013): 

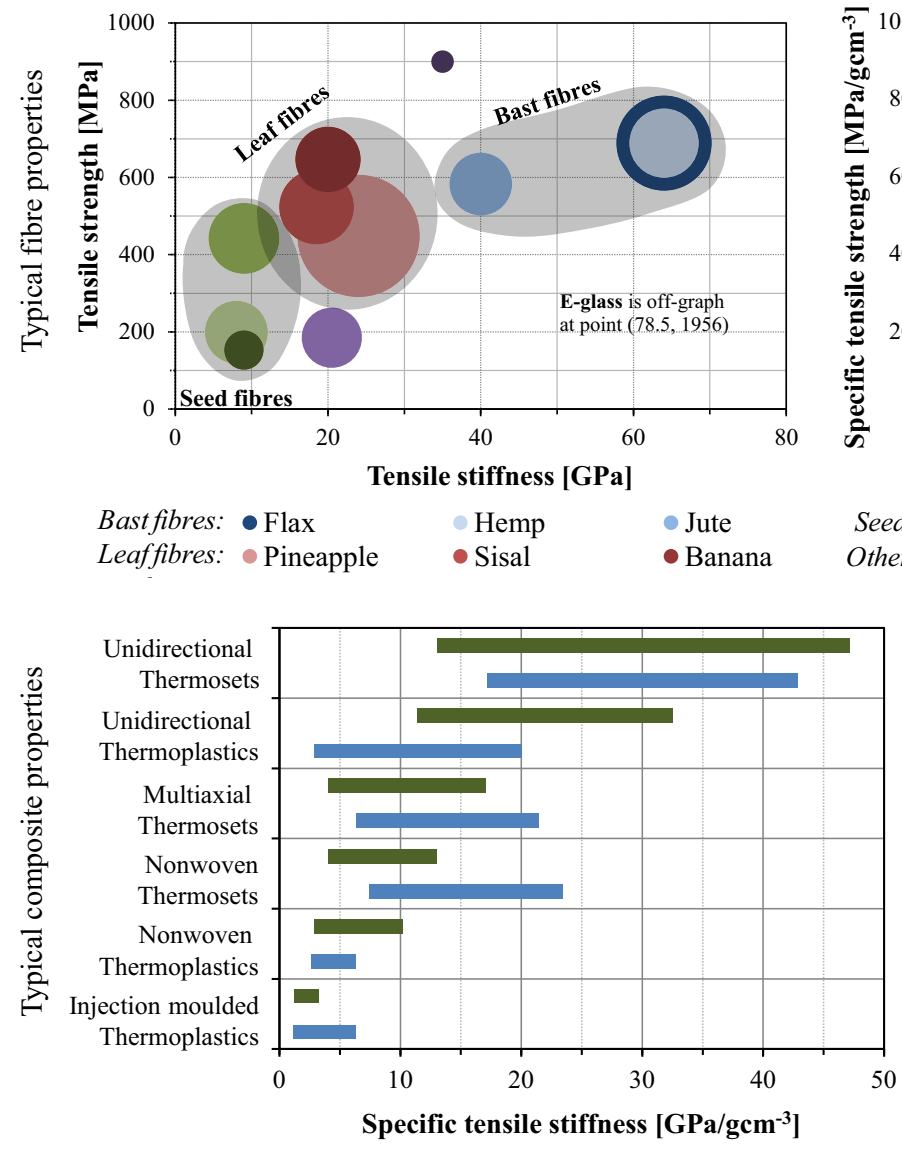

PFRPs

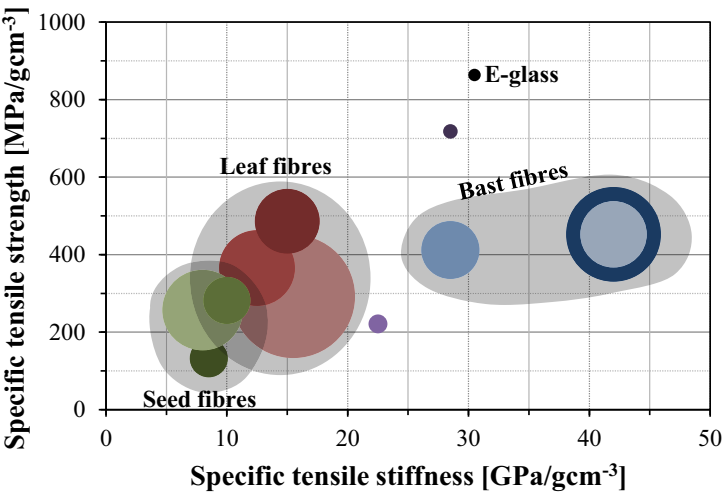

Seed fibres: - Cotton $\quad$ Oil palm Other fibres: - Bamboo $\bullet$ Wood pulp

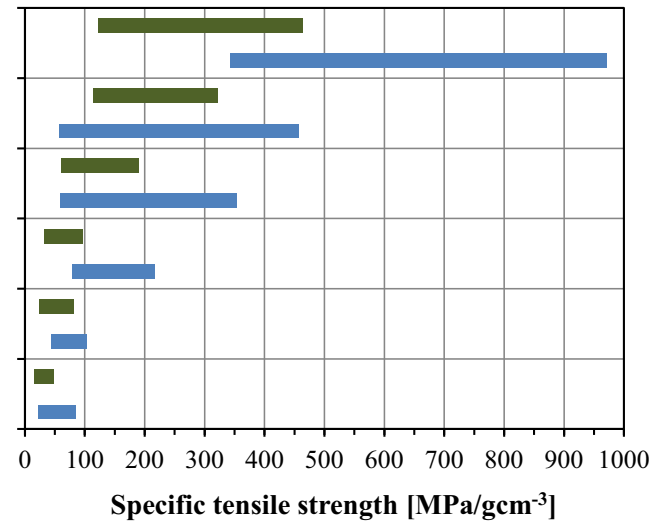

GFRPs

Fig. 1 Comparison of typical strength and stiffness performance of various plant fibres and their reinforced composites (PFRPs) against E-glass and their reinforced composites (GFRPs). Adapted from Shah (2014)

1. PFRPs are go-to-solutions for automotive interior components, providing opportunities in (a) weight reduction due to good specific properties (Fig. 1), (b) cost saving, and (c) end-of-life disposal by incineration (Koronis et al. 2013; Mougin et al. 2009)

2. Plant fibres are abundant and low cost, and consequently PFRPs products (e.g. decking) have shown exceptional growth in the building and construction industry (Dittenber and Gangarao 2012)

3. The high specific stiffness (Fig. 1), high vibration damping performance and aesthetic properties of PFRPs has led to a number of innovations in consumer goods, including musical instruments and high-performance sporting equipment (e.g. boards and rackets) (Pil et al. 2016)
While PFRPs are being considered for many more applications, particularly in structural components (Shah et al. 2013a), there are several major bottlenecks. These include issues relating to long-term durability (vis. moisture and fire performance) and lack of extensive design data (particularly for complex loads, e.g. fatigue and creep, and complex behaviours, e.g. non-linear stress-strain response) (Bensadoun et al. 2016; Shah 2013; Wambua et al. 2003). Stemming from the latter is another important bottleneck-our inability to accurately model the properties and behaviour of plant fibres (Trivaudey et al. 2015) and their composites (Andersons et al. 2015; Shah 2016; Summerscales et al. 2013; Virk 2010; Virk et al. 2012).

It is highly desirable to be able to predict composite properties (and behaviour) from data on fibre properties. This provides a cost-effective and time-saving 
route in developing optimised materials with reliable behaviour. Currently, this is not possible with plant fibres and PFRPs. This is in part due to the naturally variable, stochastic properties of plant fibres, but also due to a serious lack of studies relating plant fibre properties to composite behaviour.

In developing PFRPs, there are numerous studies that have measured the mechanical properties of single plant fibres (such as Andersons et al. 2005; Aslan et al. 2011; Bachtiar et al. 2010; Charlet et al. 2007b; Defoirdt et al. 2010; Hu et al. 2010; Virk et al. 2009b) or PFRPs (such as Madsen et al. 2007; Roe and Ansell 1985; Wambua et al. 2003). Researchers who exclusively study the mechanical properties of PFRPs commonly apply the rule of mixtures (ROM) model to 'back-calculate' the mechanical properties of the reinforcing fibres. This allows appreciating the reinforcing potential of plant fibres by determining fibre properties from composite properties. Expectedly, the ROM (Eqs. 1 and 2) has become a widely used micromechanical model for PFRPs (Garkhail et al. 2000; Madsen et al. 2009; Shah 2013; Shah et al. 2012b; Summerscales et al. 2013; Virk et al. 2012).

$E_{c}=\eta_{l E} \eta_{o} v_{f} E_{f}+v_{m} E_{m}$

$\sigma_{c}=\eta_{l s} \eta_{o} v_{f} \sigma_{f}+v_{m} \sigma_{m}^{\prime}$

where, $E_{f}$ and $E_{m}$ are the fibre and matrix modulus, $\sigma_{f}$ and $\sigma_{m}^{\prime}$ are the fibre and matrix tensile stress (at the fibre failure strain), $v_{f}$ and $v_{m}$ are the fibre and matrix volume fraction, $\eta_{l E}$ and $\eta_{l S}$ are the reinforcement length distribution factors for stiffness and strength, and $\eta_{o}$ is the reinforcement orientation distribution factor. For simplification, the length and orientation distribution factors are commonly assumed to be unity for yarn-reinforced, unidirectional PFRPs (Baets et al. 2014; Madsen et al. 2007; Oksman et al. 2002; Virk et al. 2012; Weyenberg et al. 2006). We also note here that the modified Kelly-Tyson equation (Eq. 2) is generally limited to (near-) unidirectional composites as significant fibre misalignment loads the (weaker) fibre-matrix interface rather than the composite as a homogeneous medium.

According to the authors' knowledge, other than the critical study described henceforth, there are only four studies in literature (Charlet et al. 2007a, 2010; Oksman et al. 2002; Virk et al. 2012) which inspect the mechanical properties of both the single plant fibres and their unidirectional PFRPs. These studies also compare the experimentally-determined (through single fibre tests) fibre properties with the predicted ('back-calculated') fibre properties. Peculiarly, in all cases, the experimentally measured fibre properties are consistently found to be significantly different from the predicted properties (at $5 \% \alpha$ significance level, based on two-talied t-tests); see Table 1 for an amalgamation of literature findings. On the other hand, the experimentally measured and 'back-calculated' properties of synthetic fibres (such as E-glass and carbon) tend to be concurrent (Harris 1999; Shah et al. 2014).

This manuscript conducts an independent analysis, and then outlines and evaluates possible sources of the observed phenomenon. The discussion aims to be a useful premise for future studies improving models (including the ROM) for natural fibre composites, and enabling reliable prediction of composite properties from fibre data.

\section{Experimental procedure}

Materials and preparation

Bobbins of Linum usitatissimum flax rovings (396 tex, 20 tpm) and Corchorus olitorius tossa jute yarns (206 tex, $190 \mathrm{tpm}$ ) were supplied by Safilin (France) and Janata and Sadat Jute Ltd (Bangladesh), respectively. Properties of the yarns are detailed in Shah et al. (2012c, 2014). Unidirectional mats were prepared using a drum-winding system and hydroxyethylcellulose binding agent (Shah et al. 2014). Aligned composite laminates $(250 \mathrm{~mm}$ square, 3-3.5 mm thick) of varying fibre volume fractions were then fabricated using the vacuum infusion technique in a rigid aluminium mould tool. Resin infusion was carried out under vacuum at 200-300 mbar absolute pressure. The matrix used was an orthophthalic unsaturated polyester resin (Reichhold Norpol 420-100), mixed with $0.25 \mathrm{wt} \%$ NL49P accelerator and $1 \mathrm{wt} \%$ Butanox M50 MEKP initiator. Post cure was carried out at $55{ }^{\circ} \mathrm{C}$ for $6 \mathrm{~h}$ after ambient cure for $16 \mathrm{~h}$. From the manufacturer's datasheet, the polyester resin has a tensile modulus $E_{m}$ of $3.7 \mathrm{GPa}$, tensile strength $\sigma_{m}$ of $70 \mathrm{MPa}$ and failure strain $\varepsilon_{m}$ of $3.5 \%$. 


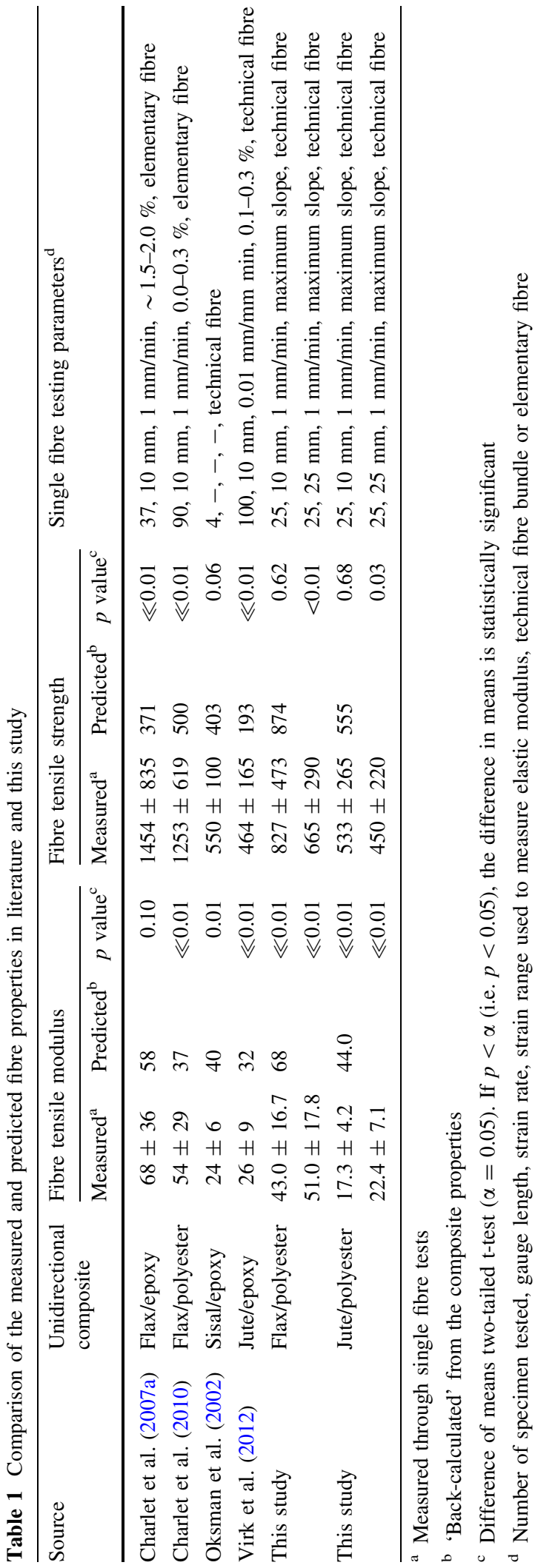

Test methods

Single fibres, separated carefully from yarns, were glued onto a card frame (using Araldite Rapid adhesive) and their 'apparent' diameter was determined from the mean of three measurements along the fibre length using an optical microscope. Single fibre tests were then conducted on a Hounsfield testing machine equipped with a $5 \mathrm{~N}$ load cell, at a cross-head speed of $1 \mathrm{~mm} / \mathrm{min}$. 25 samples were tested at gauge lengths of $10 \mathrm{~mm}$ and $25 \mathrm{~mm}$. The stress-strain curve of each fibre was used to measure its tensile modulus $E_{f}$ (the maximum slope), ultimate tensile strength $\sigma_{f}$, and failure strain $\varepsilon_{f}$.

For the PFRP laminates, tensile tests were conducted according to ISO 527-4:1997 using an Instron 5985 testing machine, equipped with a $100 \mathrm{kN}$ load cell and an extensometer. At least six $250 \mathrm{~mm}$ long and $15 \mathrm{~mm}$ wide specimens were tested at a crosshead speed of $2 \mathrm{~mm} / \mathrm{min}$. The stress-strain curve of each specimen was used to measure its tensile modulus $E_{c}$ [in the strain range of $0.025-0.10 \%$, following (Baets et al. 2014; Shah et al. 2012a)], tensile strength $\sigma_{c}$ and failure strain $\varepsilon_{c}$.

\section{Results}

Table 1 presents the measured single plant fibre tensile properties. For both flax and jute fibres, it is evident that the mean tensile stiffness is higher and the mean tensile strength is lower when tested at a longer gauge length. However, due to the large standard deviations (coefficient of variance of 25-60\%), the difference in means is not statistically significant (at $\alpha=0.05$ ). These observations are in agreement with literature findings (Defoirdt et al. 2010; Virk et al. 2009b). At a gauge length of $10 \mathrm{~mm}$, the measured tensile stiffness and strength is $43.0 \mathrm{GPa}$ and $827 \mathrm{MPa}$ for flax fibres, and 17.3 GPa and $533 \mathrm{MPa}$ for jute fibres.

The influence of fibre volume fraction on PFRP tensile stiffness and strength is illustrated in Figs. 2 and 3 ; a strong linear correlation $\left(\mathrm{R}^{2}>0.95\right)$ is observed. Applying the ROM's (Eqs. 1 and 2, with $\left.\eta_{l E}, \eta_{l S}, \eta_{o}=1\right)$ to the results in Figs. 2 and 3 yields the 'back-calculated' modulus and strength for (1) flax and (2) jute fibres to be (1) $68.0 \mathrm{GPa}$ and $874 \mathrm{MPa}$, and (2) $44.0 \mathrm{GPa}$ and $555 \mathrm{MPa}$, respectively (Table 1). 


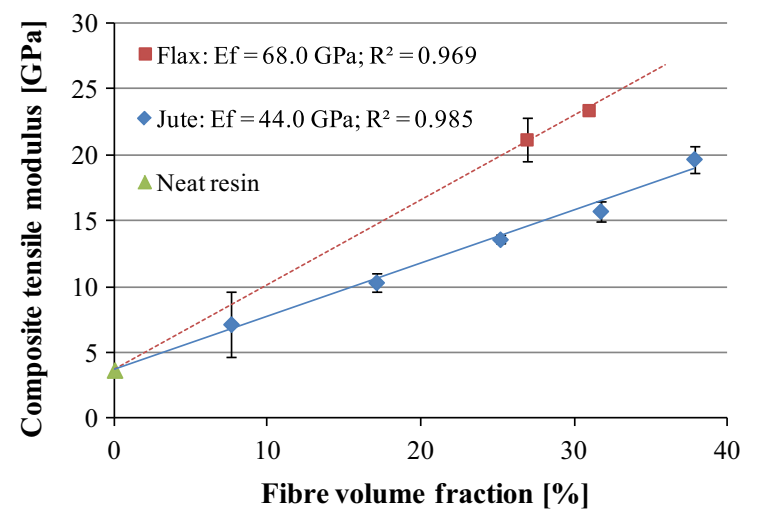

Fig. 2 Rule of mixtures relation for tensile modulus (Eq. 1) of unidirectional jute and flax polyester composites at various volumetric compositions

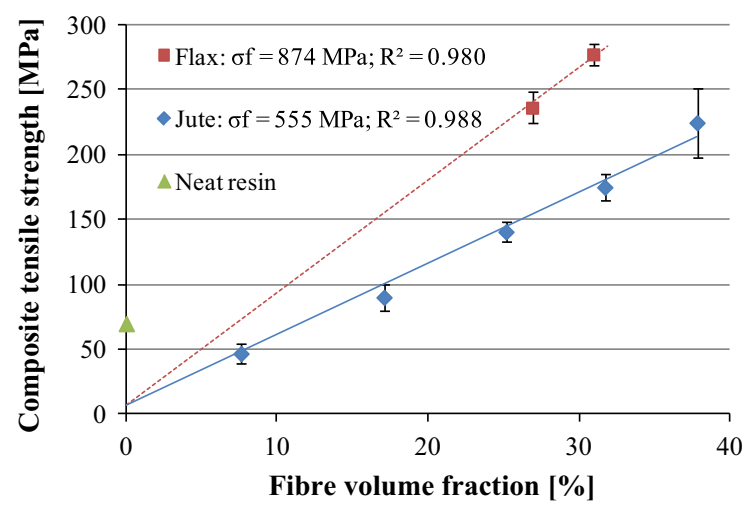

Fig. 3 Rule of mixtures relation for tensile strength (Eq. 2) of unidirectional jute and flax polyester composites at various volumetric compositions

Comparing the measured and predicted fibre properties (Table 1), it is found that for both flax and jute fibres:

1. the predicted fibre stiffness is significantly different (at $\alpha=0.05$ ) from the measured fibre stiffness at both gauge lengths,

2 . the predicted fibre strength is significantly different (at $\alpha=0.05$ ) from the measured fibre strength at a gauge length of $25 \mathrm{~mm}$, but insignificantly different from the measured fibre strength at a smaller gauge length of $10 \mathrm{~mm}$, and

3. the predicted values are higher than the mean of the measured values, particularly in the case of fibre stiffness.

The observations that the measured and predicted fibre properties are significantly different are consistent with the other literature studies introduced earlier (Charlet et al. 2007a, 2010; Oksman et al. 2002; Virk et al. 2012). However, as is clear from Table 1, it is not always consistent amongst the studies whether measured fibre properties are higher or lower than predicted properties. This indicates that a variety of possible sources may lead to the observed phenomenon, depending on the protocols of the studies.

\section{Discussion}

The discrepancy between the measured and predicted values for the plant fibre reinforcements observed in literature and our study (Table 1) would be categorically attributable to, either or both, (1) the experimental error in measuring the tensile properties of plant fibres and their composites, and (2) the suitability, if not validity, of the ROM for PFRPs. The possible sources within each category are listed in Table 2. In many cases, there would be an overlap between and within categories. In addition, in some cases, the effects may be different on strength and stiffness.

\section{Measurement conditions}

The first question that arises is 'what are we testing?' Fibre extraction processes, including retting, decortification, scutching, and hackling, almost always reveal technical fibre bundles rather than individual elementary fibres. One of the most important nomenclature issues in plant fibre testing is the need for clarity between elementary fibres and technical fibres; the latter consist of bundles of multiple elementary fibres bound together by pectin-rich middle lamella (Fig. 4). Tests on technical fibre bundles tend to reveal substantially lower mechanical properties (both stiffness and strength) than elementary fibres (Bos et al. 2002; Oksman et al. 2002; Zeng et al. 2015). Indeed, many fibre types, such as jute, sisal and hemp, are difficult to (completely) separate into elementary fibres from the technical fibres. Hence, it is common to use technical fibres to manufacture plant fibre composites. However, it is debatable whether the 'reinforcing unit' within a composite is a technical fibre or elementary fibre (or perhaps neither, or both due to any averaging effects). Scientists measuring the properties of elementary fibres will often separate 
Table 2 Possible sources of observed differences in measured and predicted fibre properties

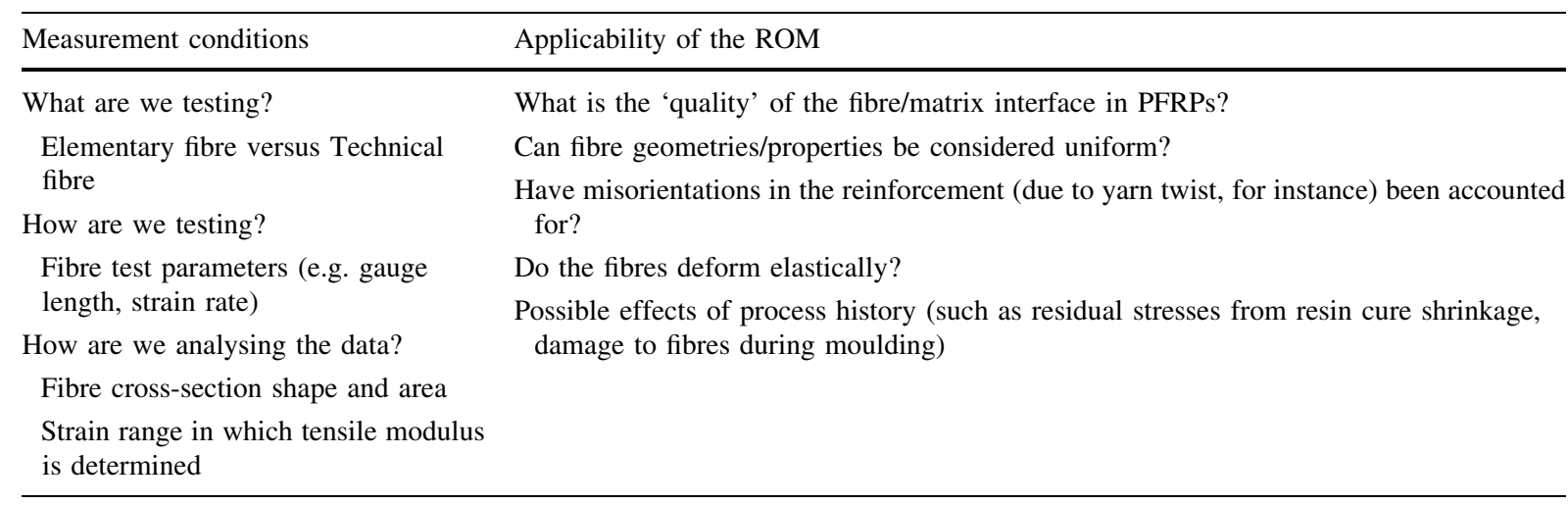

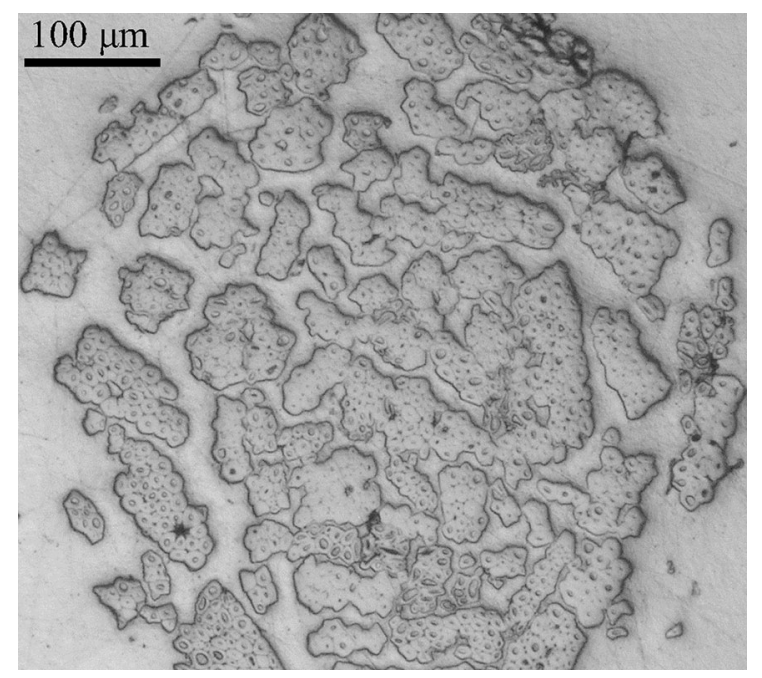

Fig. 4 Microscopy image of the tested tossa jute staple yarn consisting of multiple technical fibres. The irregular crosssection technical fibres are themselves bundles of elementary fibres. Each elementary fibre is visible with a central lumen, and a thick lignified secondary cell wall

elementary fibres from technical fibre bundles by hand (Charlet et al. 2007a, 2010).

Not only are the properties of technical fibres substantially different (lower) than elementary fibres, it is also observed from Table 1 that back-calculated (predicted) properties of the reinforcing unit fall intermediate to measured technical and elementary fibre properties. For instance, Oksman et al. (2002) measured the tensile properties of sisal technical fibres and of composites incorporating them; they found that the 'back-calculated' properties of the reinforcing unit was substantially (40-70\%) higher than that of the measured technical fibre properties (Table 1). In contrast, Charlet et al. (2007a, 2010) in their studies on flax fibres have found that the measured elementary fibre properties were substantially (up to $70 \%$ ) higher than 'back-calculated' fibre properties of composites comprising of technical fibres (Table 1). To elucidate more on this aspect, perhaps a thorough study needs to be done which examines elementary and technical fibre properties, alongside composites manufactured from both the elementary and technical fibres.

Another important aspect that the debate on the fundamental reinforcing unit raises is that in the case where composites comprise of technical fibres, interactions and damage mechanisms between elementary fibres within bundles (such as frictional sliding) (Charlet et al. 2007a; Charlet and Beakou 2011; Charlet et al. 2010) are unaccounted for by the ROM, which considers a two-scale system: fibre embedded in a matrix, as opposed to elementary fibres bound in technical fibre bundles which are embedded in a matrix. Therefore, predictions from the ROM may not be representative of a technical or elementary fibre anyway, but of an 'effective' reinforcing unit. This is not an issue for many synthetic fibres, such as glass fibres, as they are independent circular cross-section elements.

The second question that arises is 'how are we testing?' Two test parameters known to have a notable effect on measured fibre properties are specimen gauge length and applied rate of extension. In general, natural fibre tensile properties tend to increase with decreasing gauge length; the influence on strength and failure strain can be substantial at smaller gauge lengths. This has been demonstrated even 
through Weibull analysis of extensive data (such as in Virk et al. 2009a). Other than weak-link scaling effects, the selection of test gauge length is particularly important in the case of technical fibres, as the gauge length will determine whether at least one elementary fibre within the technical fibre bundle is being gripped from end to end.

Fibre testing parameters affect the measured properties which are used as benchmarks for comparison with predicted properties. Notably, the predicted fibre strength from the ROM is, strictly speaking, the fibre strength at the critical fibre length (Harris 1999). Therefore, ideally, the measured fibre strength should be at the critical fibre length as well. As this may be difficult to obtain (if the critical length is submillimetre, for example), it may be useful to estimate the fibre strength at the critical length (e.g. based on Weillbull analysis of fibre testing data at various gauge lengths) for comparison with the predicted fibre properties.

The third question that arises is 'how is the experimental raw data analysed?' Due to the irregular cross-section of plant fibres, cross-section area has been a significant source of error in many fibre testing studies. More recently, it has been demonstrated that the true cross-section area (measured through microscopy and image analysis) can be up to 1.42 to 2.55 times lower than the apparent cross-section area (calculated based on an assumed circular cross-section shape and measurement of mean diameter) (d'Almeida et al. 2012; Thomason et al. 2011, 2012; Virk 2010). This implies that measured tensile properties based on assumed circular cross-section fibres underestimate fibre properties (strength and stiffness) by $40-70 \%$. This would be a notable and most likely source of difference between measured and predicted fibre properties. Virk et al. (2012) have reported that correcting for the fibre cross-section area leads to a better (although not exact) matching in measured and 'back-calculated' jute fibre properties. Consequently, Summerscales et al. (2013) have proposed the inclusion of a fibre area correction factor in the modified rule of mixtures for natural fibre composites.

Another important source of error in differences in measured and predicted fibre stiffness is the selection of the strain range in which the fibre and composite stiffness is measured. Both plant fibres and their reinforced composites demonstrate substantial nonlinearity in tensile stress-strain response. While the stress-strain behaviour of plant fibres can be a mix of strain hardening (i.e. increasing stiffness with strain), strain softening (i.e. decreasing stiffness with strain) and linear (Fig. 5a; Pickering et al. 2007; Placet et al. 2014), leading to variations in stiffness of $\pm 30 \%$ along the stress-strain curve (Fig. 5b), plant fibre composites exhibit a substantial (up to $50 \%$ ) reduction in stiffness initially (in the strain range of 0-0.4\%) before stabilising (Fig. 5b; Bensadoun et al. 2016; Kersani et al. 2015; Shah 2016; Shah et al. 2012a). Such variations in stiffness with applied strain make it difficult to compare measured (from single plant fibre tests) and predicted (using ROM for composites) fibre stiffness. This is also because stresstransfer and damage mechanisms may be different in plant fibres and their reinforced composites (Shah 2016). Note that here we do mention 'damage', as stiffness variation with applied strain is an accepted indicator of damage accumulation, and it is wellknown that the 'yield strain' of plant fibres and their composites is as low as $0.15 \%$ (Hughes 2012; Kersani et al. 2015; Shah et al. 2012a).

Of course, there are other possible sources. This includes experimental bias; for example, Charlet et al. (Charlet et al. 2007a, 2010) have suggested the unintentional use of strongest fibres for tensile tests in their experiments.

\section{Applicability of the ROM}

Other than experimental error, discrepancies between measured and predicted properties may be a result of incorrect predictions using inappropriate models (i.e. ROM model). Here, we explore some of the basic assumptions in the ROM model and discuss them in light of plant fibres and PFRPs.

The ROM assumes a perfect interface; one of the first topics that often comes up when discussing PFRPs is the 'quality' of the fibre matrix interface. However, the interface is only an issue in (a) short fibre composites (where fibre length is at or below the critical fibre length), and (b) polyolefin-based thermoplastic composites (due to high viscosity and poor wettability/impregnation of the fibres, as well as incompatibility between non-polar matrix and relatively polar fibres, particularly when lacking chemical compatibilisers and coupling agents); refer to (Shah 2013) for detail. As all studies referred to in Table 1 employ long fibre reinforcements [much longer than 


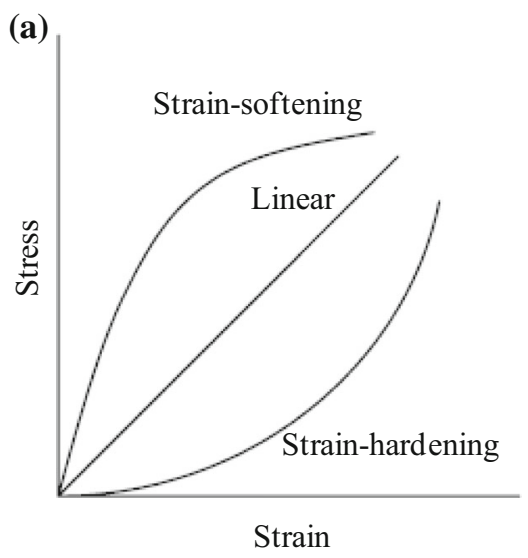

Fig. 5 Plant fibres and their reinforced composites exhibit nonlinearity in stress-strain response. a Plant fibres may show linear, non-linear (strain-softening or strain-hardening) or even multiple non-linearity in stress-strain response. Adapted from

the critical fibre length (Shah 2013; Shah et al. 2014)], and use a thermosetting matrix (with low viscosity and high polarity), the interface is not a likely source of discrepancy in predicted and measured fibre properties. This is in agreement with the assessment made by Charlet et al. (Charlet et al. 2007a, 2010). This is further supported by our observation that the ROM applies to a range of fibre volume fractions for the same input parameters (Figs. 2 and 3).

The ROM also assumes uniform fibre properties; this is certainly not the case with plant fibres, which exhibit a significant, natural, stochastic scatter in properties. While it is important to note that such a scatter in properties is not visible at the composite scale, the composite properties and fracture behaviour may be influenced more by the proportion of fibres with lower strength/stiffness, based on the weak-link scaling theory. The ROM also assumes that fibres are elastic; as mentioned earlier this is also not the case with plant fibres. Plant fibres exhibit complex mechanical behaviour, which is elasto-visco-plastic (Placet et al. 2014).

Other than assumptions at the fibre scale, assumptions at the reinforcing product scale (i.e. tow or yarn), would also affect the accuracy of prediction from the ROM. In particular, misorientation in the form of fibre waviness, yarn twist and fabric crimp may influence properties and need to be accounted for when backcalculating fibre properties. For example, Shah et al. (2013b) have proposed a modified Krenchel

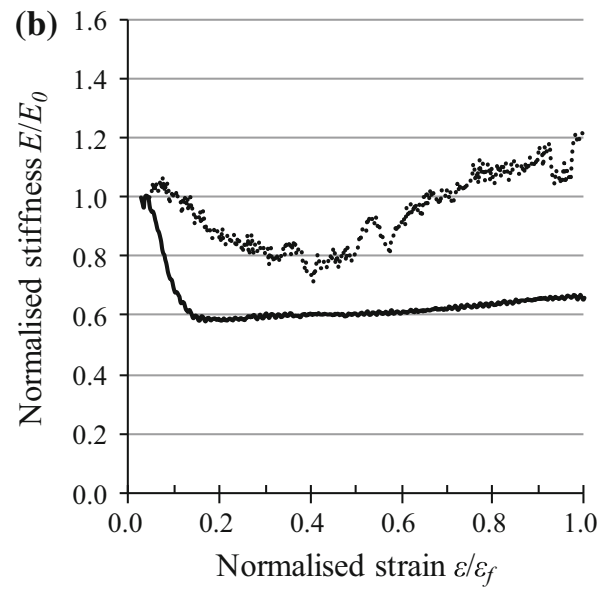

Pickering et al. (2007). b Plot of normalised stiffness against normalised strain reveals that the stiffness of the fibres (dotted line) and the composite (solid line) is not constant as a function of applied strain. Adapted from Shah (2016)

orientation distribution factor to account for misorientation due to yarn twist in plant yarn reinforced composites. Yarn twist is observed to have a notable effect on composite properties; a yarn surface twist angle of $30^{\circ}$, typical of plant fibre staple yarns, would lead to a drop in composite tensile strength by over $70 \%$. Not correcting for fibre misorientation would lead to a much smaller predicted fibre tensile strength than would be expected/measured.

Finally, process history of composite manufacture may influence the predicted fibre properties from the ROM. For example, damage of fibres (elementary or technical) during compression moulding may lead to composites with lower properties than would be expected; that is, the measured fibre properties would be higher than the back-calculated fibre properties, simply because in the latter case, the fibres have been mechanically compromised. This has been suggested by Charlet et al. (2007a, 2010) as an important factor as they observed notably lower 'back-calculated' fibre properties.

Other factors, such as the presence of voids (e.g. luminal porosity), and residual stresses due to cure shrinkage of the matrix, may also lead to discrepancies in predictions based on the ROM. However, these are not likely to be important factors; it has been shown for example that void content below $4 \%$ in PFRPs does not lead to a significant deviation in the ROM model prediction (Madsen et al. 2009; Shah et al. 2012b). However, higher porosity content, particularly at the 
fibre/matrix interface and within the matrix may lead to deviations in the model prediction (Madsen et al. 2009).

\section{Conclusions}

This study, alongside a handful of studies in literature (Charlet et al. 2007a, 2010; Oksman et al. 2002; Virk et al. 2012), have found that the experimentally determined (through single fibre tests) fibre properties are significantly different from the predicted ('backcalculated' using the ROM) fibre properties for natural fibres. While the studies do suggest potential sources of the discrepancies, there is no consensus. Of course, as testing methodologies are different in the various studies, the sources are also likely to be different.

In the discussion so far, we have explored potential origins and identified some as being key. The likely origins relating to measurement (in order of importance) are (1) error in fibre cross-section area, (2) strain range in which stiffness is determined for such non-linear materials, (3) differences in elementary and technical fibre properties, and (4) gauge length at which single plant fibre test is carried out. The likely origins relating to errors in predictions based on the ROM are (1) nonuniform fibre properties which are stochastic in nature (i.e. can be analysed statistically, but not predicted precisely), (2) misorientations in the reinforcement, and (3) effects of processing history, (4) plant fibre and PFRP behaviour is not entirely elastic (and is actually varied). The effects of some of the above origins of discrepancies are quantifiable, while others not.

The explored content in this discussion facilitates the design of a future investigation to (1) identify the sensitivity of the discrepancy between measured and predicted fibre properties to the various potential origins, (2) form a unified hypothesis on the observed phenomenon, and (3) determine whether the ROM model (in specific cases) can be improved and may be able to predict properties precisely.

While it is highly desirable to be able to predict composite properties (and behaviour) from data on fibre and matrix properties when designing with composites, we recommend that currently, a more pragmatic approach in the case of natural fibre composites is to base designs on tests on composite samples.
Open Access This article is distributed under the terms of the Creative Commons Attribution 4.0 International License (http:// creativecommons.org/licenses/by/4.0/), which permits unrestricted use, distribution, and reproduction in any medium, provided you give appropriate credit to the original author(s) and the source, provide a link to the Creative Commons license, and indicate if changes were made.

\section{References}

Andersons J, Sparnins E, Joffe R, Wallstrom L (2005) Strength distribution of elementary flax fibres. Compos Sci Technol 65:693-702

Andersons J, Modniks J, Sparnins E (2015) Modeling the nonlinear deformation of flax-fiber-reinforced polymer matrix laminates in active loading. J Reinf Plast Compos 34:248-256

Aslan M, Chinga-Carrasco G, Sørensen BF, Madsen B (2011) Strength variability of single flax fibres. J Mater Sci 46:6344-6354

Bachtiar D, Sapuan SM, Zainudin ES, Khalina A, Dahlan KZM (2010) The tensile properties of single sugar palm (Arenga pinnata) fibre. In: Paper presented at the 9th national symposium on polymeric materials, Putrajaya, Malaysia

Baets J, Plastria D, Ivens J, Verpoest I (2014) Determination of the optimal flax fibre preparation for use in unidirectional flax-epoxy composites. J Reinf Plast Compos 33:493-502

Bensadoun F, Vallons KAM, Lessard LB, Verpoest I, van Vuure AW (2016) Fatigue behaviour assessment of flax-epoxy composites. Compos Part A Appl Sci Manuf. doi:10.1016/ j.compositesa.2015.11.003

Bos H, van den Oever MJA, Peters OCJJ (2002) Tensile and compressive properties of flax fibres for natural fibre reinforced composites. J Mater Sci 37:1683-1692

Charlet K, Beakou A (2011) Mechanical properties of interfaces within a flax bundle-part I: experimental analysis. Int J Adhes Adhes 31:875-881

Charlet K, Baley C, Morvan C, Jernot JP, Gomina M, Bréard J (2007a) Characteristics of Herme's flax fibres as a function of their location in the stem and properties of the derived unidirectional composites. Compos A Appl Sci Manuf 28:1912-1921

Charlet K, Jernot JP, Moussa G, Baley C, Bizet L, Breard J (2007b) Morphology and mechanical behaviour of a natural composite: the flax fiber. In: Paper presented at the 16th international conference on composite materials (ICCM-16), Kyoto, Japan, July 8-17 2007

Charlet K, Jernot JP, Gomina M, Bizet L, Bréard J (2010) Mechanical properties of flax fibers and of the derived unidirectional composites. J Compos Mater 44:2887-2896

d'Almeida J, Mauricio MHP, Paciornik S (2012) Evaluation of the cross-section of lignocellulosic fibers using digital microscopy and image analysis. $\mathrm{J}$ Compos Mater 46:3057-3065

Defoirdt N, Biswas S, De Vriese L, Tran LQN, Acker JV, Ahsan Q, Gorbatikh L, Vuure AV, Verpoest I (2010) Assessment of the tensile properties of coir, bamboo and jute fibre. Compos A Appl Sci Manuf 41:588-595 
Dittenber D, Gangarao HVS (2012) Critical review of recent publications on use of natural composites in infrastructure. Compos A Appl Sci Manuf 43:1419-1429

Faruk O, Bledzki AK, Fink HP, Sain M (2012) Biocomposites reinforced with natural fibres: 2000-2010. Prog Polym Sci 37:1552-1596

Garkhail S, Heijenrath RWH, Peijs T (2000) Mechanical properties of natural-fibre-mat-reinforced thermoplastics based on flax fibres and polypropylene. Appl Compos Mater 7:351-372

Harris B (1999) Engineering composite materials. The Institute of Materials, London

Hu W, Ton-That MT, Perrin-Sarazin F, Denault J (2010) An improved method for single fiber tensile test of natural fibers. Polym Eng Sci 50:819-825

Hughes M (2012) Defects in natural fibres: their origin, characteristics and implications for natural fibre-reinforced composites. J Mater Sci 47:599-609

Kersani M, Lomov SV, van Vuure AW, Bouabdallah A, Verpoest I (2015) Damage in flax/epoxy quasi-unidirectional woven laminates under quasi-static tension. J Compos Mater 49:403-413

Koronis G, Silva A, Fontul M (2013) Green composites: a review of adequate materials for automotive applications. Compos B Eng 44:120-127

Lewin M (2007) Handbook of fiber chemistry, 3rd edn. CRC Press LLC, Boca Raton

Madsen B, Hoffmeyer P, Lilholt H (2007) Hemp yarn reinforced composites-II. Tensile properties. Compos Part A Appl Sci Manuf 38:2204-2215

Madsen B, Thygesen A, Liholt H (2009) Plant fibre compositesporosity and stiffness. Compos Sci Technol 69:1057-1069

Mougin G, Magnani M, Eikelenberg N (2009) Natural-fibres composites for the automotive industry: challenges, solutions and applications. Int $\mathrm{J}$ Mater Prod Technol 36:176-188

Oksman K, Wallstrom L, Berglund LA, Filho RDT (2002) Morphology and mechanical properties of unidirectional sisal-epoxy composites. J Appl Polym Sci 84:2358-2365

Pickering K, Beckermann GW, Alam SN, Foreman NJ (2007) Optimising industrial hemp fibre for composites. Compos A Appl Sci Manuf 38:461-468

Pil L, Bensadoun F, Pariset J, Verpoest I (2016) Why are designers fascinated by flax and hemp fibre composites? Compos A 83:193-205

Placet V, Cisse O, Boubakar ML (2014) Nonlinear tensile behaviour of elementary hemp fibres. Part I: investigation of the possible origins using repeated progressive loading with in situ microscopic observations. Compos Part A 56:319-327

Roe P, Ansell MP (1985) Jute-reinforced polyester composites. J Mater Sci 20:4015-4020

Shah D (2013) Developing plant fibre composites for structural applications by optimising composite parameters: a critical review. J Mater Sci 48:6083-6107. doi:10.1007/s10853013-7458-7

Shah D (2014) Natural fibre composites: comprehensive Ashbytype materials selection charts. Mater Des 62:21-31

Shah D (2016) Damage in biocomposites: stiffness evolution of aligned plant fibre composites during monotonic and cyclic fatigue loading. Compos A Appl Sci Manuf 83:160-168
Shah D, Schubel PJ, Clifford MJ, Licence P (2012a) The tensile behavior of off-axis loaded plant fiber composites: an insight on the non-linear stress-strain response. Polym Compos 33:1494-1504

Shah D, Schubel PJ, Licence P, Clifford MJ (2012b) Determining the minimum, critical and maximum fibre content for twisted yarn reinforced plant fibre composites. Compos Sci Technol 72:1909-1917

Shah D, Schubel PJ, Licence P, Clifford MJ (2012c) Hydroxyethylcellulose surface treatment of natural fibres: the new 'twist' in yarn preparation and optimization for composites applicability. J Mater Sci 47:2700-2711. doi:10.1007/ s10853-011-6096-1

Shah D, Schubel PJ, Clifford MJ (2013a) Can flax replace E-glass in structural composites? A small wind turbine blade case study. Compos Part B Eng 52:172-181

Shah D, Schubel PJ, Clifford MJ (2013b) Modelling the effect of yarn twist on the tensile strength of unidirectional plant fibre yarn composites. J Compos Mater 47:425-436. doi: $10.1177 / 0021998312440737$

Shah D, Schubel PJ, Clifford MJ, Licence P (2014) Mechanical property characterization of aligned plant yarn reinforced thermoset matrix composites manufactured via vacuum infusion. Polym Plast Technol Eng 53:239-253

Summerscales J, Virk AS, Hall W (2013) A review of bast fibres and their composites. Part 3-modelling. Compos A Appl Sci Manuf 44:32-139

Thomason J, Carruthers J, Kelly J, Johnson G (2011) Fibre cross-section determination and variability in sisal and flax and its effects on fibre performance characterisation. Compos Sci Technol 71:1008-1015

Thomason J, Gentles F, Brennan A (2012) Natural fibre cross sectional area effects on the determination of fibre mechanical properties. In: Paper presented at the 15th European conference on composite materials (ECCM-15), Venice, Italy

Trivaudey F, Placet V, Guicheret-Retel V, Boubakar ML (2015) Nonlinear tensile behaviour of elementary hemp fibres. Part II: modelling using an anisotropic viscoelastic constitutive law in a material rotating frame. Compos Part A 68:346-355

Virk A (2010) Numerical models for natural fibre composites with stochastic properties. University of Plymouth, Plymouth

Virk A, Hall W, Summerscales J (2009a) Multiple Data Set (MDS) weak-link scaling analysis of jute fibres. Compos A Appl Sci Manuf 40:1764-1771

Virk A, Hall W, Summerscales J (2009b) Tensile properties of jute fibres. Mater Sci Technol 25:1289-1295

Virk A, Hall W, Summerscales J (2012) Modulus and strength prediction for natural fibre composites. Mater Sci Technol 28:864-871

Wambua P, Ivens J, Verpoest I (2003) Natural fibres: can they replace glass in fibre reinforced plastics? Compos Sci Technol 63:1259-1264

Weyenberg I, Chitruong T, Vangrimde B, Verpoest I (2006) Improving the properties of UD flax fibre reinforced composites by applying an alkaline fibre treatment. Compos A Appl Sci Manuf 37:1368-1376

Zeng X, Mooney SJ, Sturrock CJ (2015) Assessing the effect of fibre extraction processes on the strength of flax fibre reinforcement. Compos A Appl Sci Manuf 70:1-7 